\title{
RAM-Based \\ Neural Networks
}




\section{PROGRESS IN NEURAL PROCESSING}

\section{Series Advisors}

Alan Murray (University of Edinburgh)

Lionel Tarassenko (University of Oxford)

Andreas S. Weigend (Leonard N. Stern School of Business, New York University)

Vol. 1: Neural Networks: The Statistical Mechanics Perspective Eds. Jong-Hoon Oh, Sungzoon Cho \& Chulan Kwon

Vol. 2: Neural Networks in Financial Engineering Eds. Apostolos-Paul Refenes, Yaser Abu-Mostafa, John Moody $\mathcal{E}$ Andreas Weigend

Vol. 3: Parallel Implementation of Backpropagation Neural Networks on Transputers: A Study of Training Set Parallelism by S. Saratchandran, N. Sundararajan \& S.-K. Foo

Vol. 4: Analogue Imprecision in MLP Training by Peter J. Edwards \& Alan F. Murray

Vol. 5: Applications of Neural Networks in Environment, Energy, and Health Eds. Paul E. Keller, Sherif Hashem, Lars J. Kangas \& Richard T. Kouzes

Vol. 6: Neural Modeling of Brain and Cognitive Disorders Eds. James A. Reggia, Eytan Ruppin \& Rita Sloan Berndt

Vol. 7: Decision Technologies for Financial Engineering Eds. Andreas S. Weigend, Yaser Abu-Mostafa \& A.-Paul N. Refenes

Vol. 8: Neural Networks: Best Practice in Europe Eds. Bert Kappen \& Stan Gielen 


\section{RAM-Based \\ Neural Networks}

\section{Editor}

\section{James Austin}

University of York 
Published by

World Scientific Publishing Co. Pte. Ltd.

P O Box 128, Farrer Road, Singapore 912805

USA office: Suite 1B, 1060 Main Street, River Edge, NJ 07661

UK office: 57 Shelton Street, Covent Garden, London WC2H 9HE

\section{British Library Cataloguing-in-Publication Data}

A catalogue record for this book is available from the British Library.

\section{RAM-BASED NEURAL NETWORKS}

Copyright () 1998 by World Scientific Publishing Co. Pte. Ltd.

All rights reserved. This book, or parts thereof, may not be reproduced in any form or by any means, electronic or mechanical, including photocopying, recording or any information storage and retrieval system now known or to be invented, without written permission from the Publisher.

For photocopying of material in this volume, please pay a copying fee through the Copyright Clearance Center, Inc., 222 Rosewood Drive, Danvers, MA 01923, USA. In this case permission to photocopy is not required from the publisher.

ISBN 981-02-3253-5 


\section{Preface}

This book aims to show the state of the art in RAM based networks and to introduce the reader to this mature and developing area of artificial neural networks. It is based on presentations given at the Weightless Neural Network Workshop , Canterbury, in 1995. The authors of the chapters represent the majority of active researchers in RAM based networks through out the world. While some of the papers contain in-depth research results which may only be of interest to specialist workers undertaking research in RAM based networks, many chapters contain introductory material that describe the RAM based methods at a level suitable for workers with a basic knowledge of neural networks.

The area that the book covers is popularly known by at least three names, these being RAM based networks, weightless networks and $\mathrm{N}$ tuple networks, and can be used interchangeably. Other terms can that can relate to some forms of the networks in this book are Sigma-Pi networks and Binary Networks. The reason for choosing RAM based networks as the title, is because all the networks have some form of a Random Access Memory structure (RAM) in their architecture, where a RAM is the universal storage system used in current computer systems and is the main implementation model for the networks. It also reflects the major strength of RAM based systems which is there simple implementation in dedicated and high speed hardware. The term weightless networks reflects the fact that RAM based networks can be expressed purely as a logic expression with no 'weights' in the conventional neural network sense. In this case learning is seen as determining the logic function required to map the inputs to the outputs of the network under the conditions laid down in the training set. The term $\mathrm{N}$ tuple networks comes from the origins of the methods given by Bledsoe and Browning and their approach to selecting inputs for the network.

RAM based networks have existed for some time. Originally termed $\mathrm{N}$-Tuple methods developed by Bledsoe and Browning in 1959 and being studied for some years before loosing favour in the late 1960's. They were then picked up by Igor Aleksander in the UK in the early 1970's where there simple implementation in Random Access Memories was identified and explored. His work, lead to a number of new concepts which some of his students explored and developed. In the 1980's neural networks emerged from the dark ages of the subject and the general interest in all forms of neural networks took off, including research in RAM based systems. The area has mostly been studied in the UK with one or two notable exceptions, and is now an accepted and mature subject with a number of successful commercial applications.

In terms of theory $\mathrm{N}$ tuple methods have had a hard time, mainly due to the difficulty in dealing with the combinatorial explosion found in most mathematical approaches to the analysis of the methods. This, along with there unique construction has put off many researchers from studying them. However, this has not stopped others taking a more pragmatic approach to the area. showing how useful problems can be 
solved and high performance systems can be implemented. In addition, the book contains many useful pointers to the formal analysis of RAM based networks.

The book is structured into three sections, each introduced by an overview of the papers in the section. Section 1 contains chapters which introduce and/or compare methods known as RAM based. Section 2 presents work that extends the basic RAM based understanding and methods. Finally Section 3 contains chapters that are mainly concerned with applications of RAM based methods. However, many of these also extend the basic techniques and show, for example, how the methods may be implemented.

I would like to thank a number of people who helped in the production of this book. In particular David Bisset and the original panel who reviewed the papers for the Weightless Neural network Conference where many of the chapters saw there first drafts. Thanks goes to Aaron Turner, who checked all the latex of the chapters, my secretary, Christine Linfoot for chasing all the Authors, and finally the members of the Advanced Computer Architecture Group for reading and helping with comments on the chapters.

Jim Austin, York, May 1997 


\section{Contents}

Preface

\section{Section 1: RAM-Based Methods}

1 Introduction

1.1 RAM-Based Neural Networks, a Short History

J. Austin

1.2 From WISARD to MAGNUS: A Family of Weightless Virtual Neural Machines

I. Aleksander

1.3 A Comparative Study of $\mathrm{GSN}^{f}$ Learning Methods

A. C. P. L. F. De Carvalho, M. C. Fairhurst, D. L. Bisset

1.4 The Advanced Uncertain Reasoning Architecture, AURA

J. Austin, J. V. Kennedy, K. Lees

\section{Section 2: Extensions to N-Tuple Theory}

2 Introduction

2.1 Benchmarking N-Tuple Classifier with StatLog Datasets

M. Morciniec, R. Rohwer

2.2 Comparison of Some Methods for Processing "Grey Level" Data in Weightless Networks

R. J. Mitchell, J. M. Bishop, S. K. Box, J. F. Hawker

2.3 A Framework for Reasoning About RAM-Based Neural Networks for Image Analysis Applications

G. Howells, D. L. Bisset, M. C. Fairhurst

2.4 Cross-Validation and Information Measures for RAM-Based Neural Networks

T. M. Jфrgensen, S. S. Christensen, C. Liisberg 
2.5 A Modular Approach to Storage Capacity

P. J. L. Adeodato, J. G. Taylor

2.6 Good-Turing Estimation for the Frequentist N-Tuple Classifier

M. Morciniec, R. Rohwer

2.7 Partially Pre-calculated Weights for Backpropagation Training of RAM-Based Sigma-Pi Nets

R. Neville

2.8 Optimisation of RAM Nets Using Inhibition Between Classes

T. M. Jorgensen

2.9 A New Paradigm for RAM-Based Neural Networks

G. Howells, D. L. Bisset, M. C. Fairhurst

\section{Section 3: Applications of RAM-Based Networks}

3 Introduction

3.1 Content Analysis of Document Images Using the ADAM Associative Memory

S. E. M. O'Keefe, J. Austin

3.2 Texture Image Classification Using N-Tuple Coding of the Zero-Crossing Sketch

L. Hepplewhite, T. J. Stonham

3.3 A Compound Eye for a Simple Robotic Insect J. M. Bishop, D. A. Keating, R. J. Mitchell

3.4 Extracting Directional Information for the Recognition of Fingerprints by pRAM Networks

T. G. Clarkson, Y. Ding

3.5 Detection of Spatial and Temporal Relations in a Two-Dimensional Scene Using a Phased Weightless

Neural State Machine

P. Ntourntoufis, T. J. Stonham 
3.6 Combining Two Boolean Neural Networks for Image Classification

A. C. P. L. F. De Carvalho, M. C. Fairhurst, D. L. Bisset

3.7 Detecting Danger Labels with RAM-Based Neural Networks

C. Linneberg, A. W. Andersen, T. M. Jørgensen,

S. S. Christensen

3.8 Fast Simulation of a Binary Neural Network on a Message Passing Parallel Computer

T. Macek, G. Morgan, J. Austin

3.9 C-NNAP: A Dedicated Processor for Binary Neural Networks

J. V. Kennedy, J. Austin, R. Pack, B. Cass

Author Affiliations 